\title{
An Evolutionary Medicine Approach to Understanding Factors That Contribute to Chronic Obstructive Pulmonary Disease
}

\author{
Kazutetsu Aoshiba ${ }^{\text {a }}$ Takao Tsuji $^{\mathrm{a}}$ Masayuki Itoh $^{\mathrm{a}}$ Kazuhiro Yamaguchi $^{\mathrm{b}}$ \\ Hiroyuki Nakamura ${ }^{a}$ \\ a Department of Respiratory Medicine, Tokyo Medical University Ibaraki Medical Center, Inashiki, and ${ }^{\mathrm{b}}$ Comprehensive \\ and Internal Medicine, Tokyo Women's Medical University Medical Center East, Tokyo, Japan
}

\section{Key Words}

Biological evolution - Chronic obstructive pulmonary disease $\cdot$ Disease susceptibility $\cdot$ Evolutionary medicine . Reproduction

\begin{abstract}
Although many studies have been published on the causes and mechanisms of chronic obstructive pulmonary disease (COPD), the reason for the existence of COPD and the reasons why COPD develops in humans have hardly been studied. Evolutionary medical approaches are required to explain not only the proximate factors, such as the causes and mechanisms of a disease, but the ultimate (evolutionary) factors as well, such as why the disease is present and why the disease develops in humans. According to the concepts of evolutionary medicine, disease susceptibility is acquired as a result of natural selection during the evolutionary process of traits linked to the genes involved in disease susceptibility. In this paper, we discuss the following six reasons why COPD develops in humans based on current evolutionary medical theories: (1) evolutionary constraints; (2) mismatch between environmental changes and evolution; (3) co-evolution with pathogenic microorganisms; (4) life history tradeoff; (5) defenses and their costs, and (6) reproductive success at the expense of health. Our perspective pursues evolution-
\end{abstract}

ary answers to the fundamental question, 'Why are humans susceptible to this common disease, COPD, despite their long evolutionary history?' We believe that the perspectives offered by evolutionary medicine are essential for researchers to better understand the significance of their work.

(c) 2015 S. Karger AG, Basel

\section{Introduction}

Chronic obstructive pulmonary disease (COPD) is a common disease that causes 2.9 million deaths annually worldwide, and it is ranked as the third leading cause of death of humans [1]. In COPD, inhalation of cigarette smoke and air pollutants induces chronic inflammation of the lungs, and excessive oxidants and proteases cause the destruction of the alveoli (pulmonary emphysema) and fibrosis of the peripheral airways, leading to airflow obstruction (Global Initiative for Chronic Obstructive Lung Disease) [2]. While cigarette smoking is the most common risk factor for COPD, biomass smoke, occupational exposures and genetic risk factors, such as $\alpha_{1^{-}}$ antitrypsin deficiency, are also important [2]. While a number of studies have been conducted on the pathogenesis of COPD, examining factors such as cigarette smoking, biomass smoke exposure, genetic factors and inflam-

\section{KARGER 125}

(c) 2015 S. Karger AG, Base

0025-7931/15/0893-0243\$39.50/0
Prof. Kazutetsu Aoshiba, MD

Department of Respiratory Medicine

Tokyo Medical University Ibaraki Medical Center

3-20-1, Chuou, Ami, Inashiki, Ibaraki 300-0395 (Japan)

www.karger.com/res 
Fig. 1. Comparison between the avian unidirectional respiratory system (a) and the human bidirectional respiratory system (b). Reproduced with permission from West et al. [18].

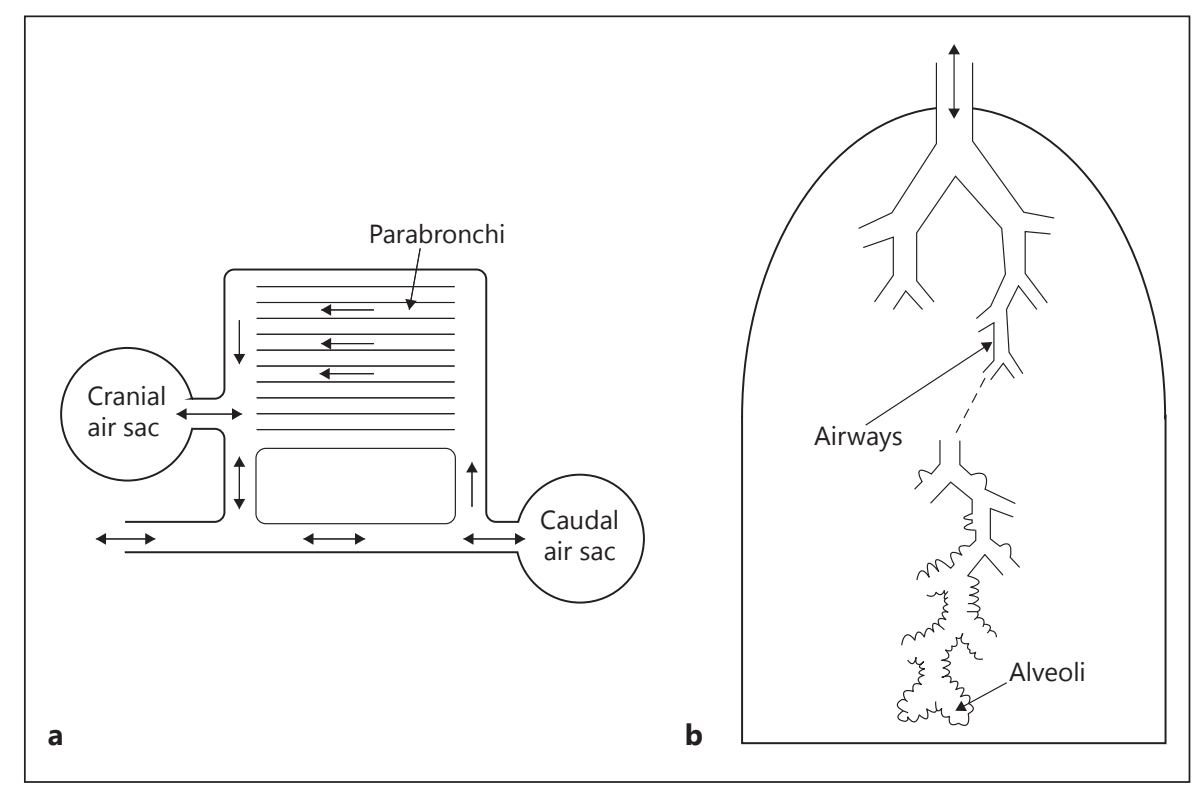

mation, the reasons why COPD exists and the reason why it develops in humans have hardly been studied. Even though humans are supposed to have obtained a delicate structure and excellent function of the lung throughout the course of a long evolutionary process, many modern human beings develop COPD. Why does the common disease, COPD, develop in humans despite their evolution over a long course in history? According to a recent report, the heritability of COPD is as high as $37 \%$ [3]; why have humans acquired this genetic predisposition?

There are proximate and ultimate factors in the etiology of disease. Approaches based on experiments and investigations are required to elucidate underlying proximate mechanisms that lead to the development of a disease. On the other hand, evolutionary (Darwinian) medical approaches are required to explain the ultimate, or evolutionary, causes such as why a disease is present and why a disease develops in humans [4-16]. Evolution is not a goaloriented phenomenon. According to the concepts of evolutionary medicine, diseases are present because of natural selection during the evolutionary process of traits that lead to genetic susceptibility to these diseases. For example, various alleles responsible for genetic predispositions to diseases may have become fixed in populations by the process of natural selection, while being transmitted through generations. Recently, Nesse et al. [5-9], pioneers of evolutionary medicine, have proposed that there are six evolutionary reasons for the acquisition of disease susceptibility traits: (1) evolutionary constraints; (2) mismatch between environmental changes and evolution; (3) co-evolution with pathogenic microorganisms; (4) life history trade-off; (5) defenses and their costs, and (6) reproductive success at the expense of health. In this paper, we have focused on smoking-induced COPD, because cigarette smoking is the best studied risk factor for COPD. We attempt to explain why humans are susceptible to COPD from the standpoint of evolutionary medicine.

\section{Evolutionary Constraints on Selection}

There is a constraint on the evolution of organisms in that the inadequacies of organogenesis cannot be corrected by going back to earlier stages of phylogeny. For example, the eyeballs of vertebrates have the disadvantage that the sites of entry of the blood vessels and nerves into the retina are blind spots and are susceptible to retinal detachment; however, organogenesis is path dependent, which means the eyeball cannot evolve into a form that does not contain any blind spots by going back through the evolutionary path to cephalopods [10].

A structural inadequacy of the human respiratory system is that it is bidirectional, in that the lung has both gas exchange and ventilatory functions; therefore, both inspired and expired air pass through the same space (fig. 1). As a result, particulate matter from cigarette smoke tends to become deposited in the bronchioles and alveoli, where airflow velocity is reduced $[17,18]$. On the other hand, 
Fig. 2. Biological state index (Ibs) values over the past 15,000 years of human evolution (adapted from Ruhli and Henneberg [27]). The index value is a probability that an average person will be able to fully participate in reproduction of the next generation. The lower index values, the greater the opportunity for natural selection. $d_{x}=A$ fraction of dying people of age $\mathrm{x} ; \mathrm{S}_{\mathrm{x}}=\mathrm{re}$ productive value of a person of age $\mathrm{x}$ (for example, $\mathrm{S} 65=0$, while $\mathrm{S} 15=1$ ). This figure illustrates that in the Stone Age there was a very significant opportunity for the process of natural selection because of high levels of differential mortality that allowed less than half of the individuals born to pass on their genes to the next generation, eliminating the other half [27].

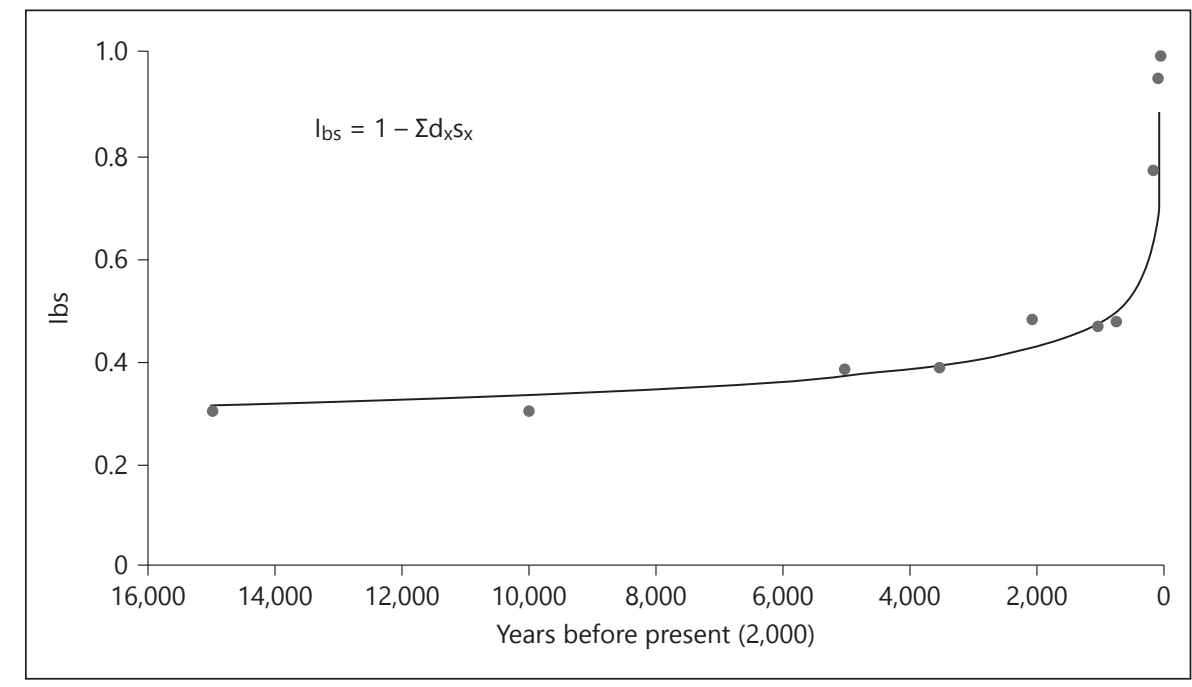

the avian lung has a unidirectional respiratory system in which the air leaving the air sacs (ventilation area) flows continuously in a unidirectional manner through the parabronchi (ventilation area). Therefore, the airflow velocity is not reduced and particulates are not easily deposited $[17,18]$. Furthermore, human alveoli have the disadvantage that they, unlike the avian parabronchi, repeatedly expand and contract, which makes them vulnerable to mechanical injury and ventilation-perfusion ratio inequality [18]. However, humans cannot correct these structural inadequacies by going back on the phylogenetic tree to the stage of birds in order to acquire a unidirectional respiratory system.

One of the biochemical inadequacies of the human lung is that elastin fibers do not regenerate; therefore, the elasticity of the emphysematous lung cannot be restored [1921]. While the durability of human lung elastin is as long as the lifetime of individuals [22], elastin fibers in the adult lung cannot regenerate, because of the reduced ability of the lung to produce tropoelastin or to coacervate/crosslink $[19,20,23]$. The assumed evolutionary reason behind this is that the selection pressure to acquire regeneration competence is weak, because of the long durability of the elastin fibers. Alternatively, it could be assumed that elastin has acquired long durability in its evolution to avoid the enormous costs of regeneration of the complex fiber structure. Similarly, the eye lens crystalline, another long-life protein, has been reported to have long durability, but limited capacity for regeneration, resulting in increased susceptibility of the elderly to developing cataracts $[24,25]$.

Another constraint on selection is that the genes responsible for diseases in the elderly are less susceptible to

Evolutionary Medicine Approach to COPD natural selection. This has been explained as being due to the small number of elderly individuals in earlier times, and the fact that even if the carriers of the genes responsible for diseases in the elderly survived to old age, they would have already left offspring (i.e. the genes would have been transmitted to their offspring before the diseases had a chance to manifest) [26] (see the Life History Trade-Off section below). The force of selection is stronger during the reproductive period than in the postreproductive period. If COPD was a disease of the young, it might not exist today. This can be explained as follows. It has been argued that exposure to biomass smoke is a risk factor for COPD, particularly in young individuals and women [2]. If the young individuals in the Stone Age had inhaled biomass smoke from fires and developed COPD in their early life, genetic predispositions to COPD would have been under strong negative selection pressure (fig. 2) [27]. Exertional dyspnea would have caused a decrease in physical activity, reducing the ability to survive circumstances, such as hunting and wars, thereby reducing the chances of reproduction.

Thus, the first reason why COPD develops in humans is considered to be the inability to correct the basic design of the lung or to eliminate genetic predispositions to diseases of the elderly, because of evolutionary constraints.

\section{Mismatch with Modern Environments}

Through natural selection, organisms have acquired resistance and tolerance to toxic substances that are present in the natural world, but it takes time for humans to 
adapt themselves to environmental changes, because of the long generation time. For example, the distribution of the gene conferring tolerance to cow's milk (lactase persistence) has been under strong positive selection pressure. Nevertheless, it is speculated that it took 5,00010,000 years before the prevalence of cow's milk resistance alleles increased to $99 \%$ in a population $[12,28]$.

Humans have continuously used fire since they evolved into Homo sapiens approximately 150,000 years ago, and they are supposed to have gradually adapted themselves to biomass smoke particulates. However, it has been only 500 years since smoking, which is associated with the production of a large amount of particulates (15-40 mg/cigarette) [29], became prevalent worldwide, with world cigarette consumption increasing by a factor of 1,000 in the last 100 years from a few billion per year in 1900 to present values of approximately 5.5 trillion worldwide [30]. The number of human generation changes is approximately 20 over a period of 500 years, and even if humans had an allele conferring resistance to cigarette smoke, the 500 -year time period is not sufficient to fix the allele in a population.

Dependence on drugs such as nicotine is a state in which the incentive mechanisms of 'liking' and 'wanting' are hijacked by external drugs in the brain [31]. Susceptibility to nicotine dependence depends on the rate of metabolism of nicotine. For example, carriers of CYP2A6 alleles with a high rate of nicotine metabolism are more susceptible to nicotine dependence than carriers of alleles with a low rate of nicotine metabolism (CYP2A6*9, CYP2A6*12, CYP2A6*2 and CYP2A6:4) [32]. However, for the same reasons mentioned earlier, it will still take a long time before the distribution of CYP2A6 alleles in a population change so much that it reduces nicotine dependence.

Many of the genetic predispositions to COPD are considered to be conferred by alleles that originally had neutral effects, but came to have deleterious effects, because of modern environmental changes. Another presumed reason why COPD develops in humans is that humans have had no time to acquire resistance to cigarette toxicity and dependency throughout natural selection, because of the long generation time. Other examples of modern environmental changes that may influence development and progression of COPD include occupational exposures, such as organic and inorganic dusts, chemical agents and fumes, as well as diet and poverty [2]. These environmental changes, as well as cigarette and biomass smoke exposures, may affect gene expression patterns through epigenetic changes, including altered
DNA methylation, decreased levels of histone deacetylases and reduced microRNAs levels. Thus, a second potential evolutionary reason for the development of COPD in humans is a mismatch between evolution and environmental factors.

\section{Co-Evolution of the Immune System and Microorganisms}

Host-microorganism interactions are neutral, antagonistic or synergistic. The immune system is considered to have co-evolved with microorganisms. More specifically, evolution has been driven by repeated competition insofar as if a microorganism acquired a countermeasure against the immune response of a host, the host would acquire a more advanced immune response to overcome the countermeasure [33-35]. Animals with a long lifespan, such as humans, are exposed to repeated invasions by the same microorganisms, and these animals are considered to have highly developed adaptive immunity in the airways and intestinal mucosae, which are the areas most exposed to microorganismal invasion; these animals quickly cope with the invasion, as the microorganisms are recognized by the immune memory function $[34,35]$.

In COPD, the immune responses to cigarette smoke particulates, particularly adaptive immune responses, are enhanced [36]. In other words, inflammation in COPD is a state in which the sophisticated immune system that has developed as a countermeasure against microorganisms is activated by cigarette smoke. Actually, the same cells (macrophages, neutrophils and lymphocytes) and signaling molecules (pattern recognition receptors, inflammasomes, interleukin- 1 and nuclear factor- $\kappa \mathrm{B}$, for example) are activated in inflammatory responses to particulates and microorganisms [36-38]. In animal experiments, there are actually commonalities and interactions between airway inflammation caused by cigarette smoke and that caused by microorganismal invasion. For example, it has been reported that airway inflammation induced by viral pathogen-associated molecular pattern stimulation is similar to that in COPD [39], and that cigarette smoke exacerbates airway inflammation induced by viral pathogen-associated molecular patterns [40]. In addition, it has been reported that latent adenoviral infection exacerbates airway inflammation and emphysematous lesions caused by cigarette smoke [41], and that simultaneous exposure to cigarette smoke and bacteria results in the formation of lesions similar to those in COPD 
[42]. Furthermore, it has been elucidated that CXCL13 is involved in lymphoid follicle formation in the airways of COPD patients as well as in response to viral infections $[43,44]$. Also, genome-wide association studies have pointed out that many genes encoding anti-infectious mediators, such as $\beta$-defensin, chemokines and tumor necrosis factor- $\alpha$, promote the development of COPD $[45,46]$.

As described above, there are many commonalities and interactions between immune responses to cigarette smoke and those to invasion by microorganisms. Therefore, the third presumed evolutionary reason for the development of COPD in humans is that the immune system, which developed through co-evolution with microorganisms, responds strongly to cigarette smoke.

\section{Life History Trade-Off}

Genetic traits that are beneficial to the growth and health of the young are subject to positive natural selection to increase reproductive success, even if they are detrimental to the health and survival of the elderly $[47,48]$. In evolutionary medicine, this understanding, known as antagonistic pleiotropy theory, is explained as follows: 'Fitness accrues via reproductive success summed across all stages of an individual's life history, and reproductive events in early life contribute more to fitness than do those late in life' [16]. An extended postreproductive life span should evolve when postreproductive individuals can make significant contributions to the fitness of their children and grandchildren [49]. Antagonistic pleiotropic genes that have been naturally selected by such a trade-off between early- and later-life fitness are considered to cause various monogenic and polygenic diseases, a phenomenon known as life history trade-off [50]. Examples of well-known antagonistic pleiotropic genes are the allele for sickle cell anemia ( $\mathrm{Hb}-\mathrm{S})$, which increases the resistance to malaria infection, and alleles of the cystic fibrosis gene, which enhance fertility and resistance to tuberculosis and cholera infections. The nature of these alleles is considered to have led to the fixation of the heterozygous alleles that do not cause diseases in certain populations (heterozygote advantage) $[5,9,51-54]$. Here, we would like to provide three examples of life history trade-offs by antagonistic pleiotropic traits to explain why COPD develops in humans.

First, COPD patients have genetic mutations that confer susceptibility to inflammation [46]. These mutant genes conferring susceptibility to inflammation are con-

Evolutionary Medicine Approach to COPD sidered to have been distributed across populations in past ages, when the prevalence of infections was the greatest threat to life, because they increased early-life fitness by enhancing the ability to defend against infections, thereby increasing reproductive success [55]. At the present time, it is considered that if carriers of these mutant genes conferring susceptibility to inflammation experience exposure to smoke, intense inflammation will occur in the lung, increasing the risk of development of COPD in later life [55].

Second, antitrypsin deficiency caused by S- and Z-allele variants causes juvenile COPD, and it is considered that variant $\alpha_{1}$-antitrypsin polymers formed by conformational changes increase the inflammatory response, and are thereby advantageous for defense against infections [56]. Furthermore, in antitrypsin deficiency, tissue protease activity is increased, which is considered to be advantageous for the removal of microorganisms and sperm penetration through the zona pellucida of the ovum at fertilization $[57,58]$. It is considered that antitrypsin deficiency alleles were selected at a certain frequency in populations for early-life fitness because of these properties of infection defense and fertilization promotion [56-58].

Third, cellular changes, such as apoptosis and cellular senescence, are involved in the development of COPD $[59,60]$. These cellular changes are thought to act to prevent carcinogenesis in early life when cell proliferation is active, while inhibiting cell regeneration and promoting the development of diseases of the elderly, such as COPD, in later life [61-63].

Thus, the fourth presumed reason why COPD develops in humans is that gene and cell traits that have been naturally selected to increase early-life fitness have antagonistic (negative) effects in later life.

\section{Costs of Defense Responses and Tolerance}

Inflammation does not only offer the benefit of defending the host against microorganisms, but it also entails the cost of collateral tissue damage by reactive oxygen species (ROS) and the risk of the systemic inflammatory response syndrome, chronic inflammatory diseases and autoimmune diseases [64]. The cost-benefit balance of inflammation is adjusted in organisms at a level that is optimal for the individuals' survival according to the environment $[35,65]$ (fig. 3a). In past human history, the prevalence of infections has been a major threat to life, and high-cost (but high-benefit) inflammatory traits are 


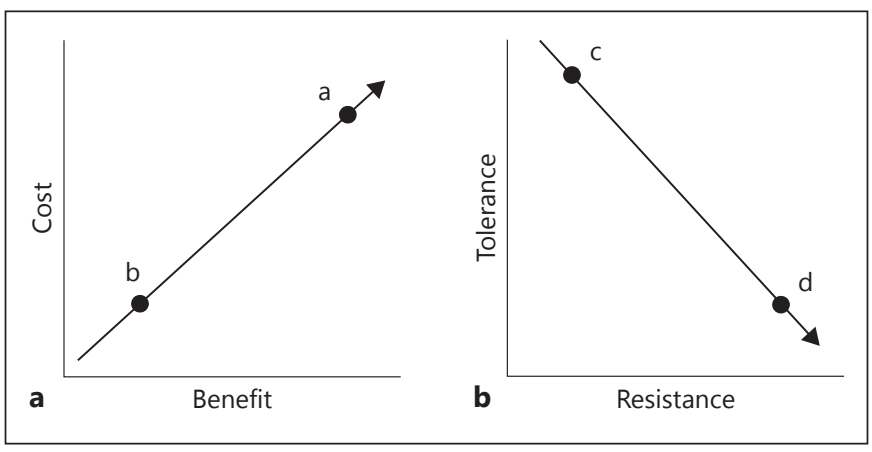

Fig. 3. The cost-benefit (a) and resistance-tolerance (b) relationships in the defense responses. a The cost-benefit balance of inflammation in organisms is set to be optimal for the individuals' survival, according to the environment. In humans, the prevalence of infections has been a threat to life, and high-cost but high-benefit inflammatory traits (a) have been naturally selected so that microorganisms can be effectively removed. a = High-cost and high-benefit inflammation; $b=$ low-cost and low-benefit inflammation. $\mathbf{b}$ There is a trade-off relationship between resistance and tolerance. Organs with low resistance to microorganisms (for example, the large intestine) have high tolerance (c); on the other hand, organs with high resistance to microorganisms (for example, the lower respiratory tract) have low tolerance (d).

considered to have been naturally selected so that microorganisms could be effectively counteracted. However, in modern industrialized countries, false inflammatory triggers such as high-salt/high-fat dietary habits and smoking, instead of infections, are increasing. These false inflammatory triggers cause low-intensity chronic inflammation, and this is considered to induce the immunopathology of arteriosclerosis, COPD and other conditions, because high-cost inflammatory traits are maintained [66].

The costs of inflammation depend on the balance between resistance (the ability to remove microorganisms and injurious agents) and tolerance (the ability to reduce the harmful effects of microorganisms and injurious agents without removing them). There is an evolutionary trade-off relationship between resistance and tolerance $[33,67,68]$ (fig. 3b). For example, in the large intestine, which has low resistance, many microorganisms $\left(10^{10}\right.$ microorganisms, consisting of more than 100 species of commensals per gram of feces) live symbiotically, but tissue injury does not occur because of the developed tolerance. However, it is known that severe inflammation and Crohn's disease occur in the large intestine when mutations in the nucleotide-oligomerization domain 2 lead to reduced tolerance $[69,70]$. On the other hand, the lower respiratory tract has developed resistance to maintain aseptic conditions. In contrast to the large intestine, tolerance is set low as a trade-off for the developed resistance $[67,71]$. Therefore, if the resistance fails for some reason and bacteria colonize the lower respiratory tract, chronic airway lesions, such as bronchiectasis, may develop easily because of the low tolerance. A reduction in immunological tolerance and oxidative stress tolerance is involved in the development of COPD [72, 73]. Tolerance set low to give priority to resistance in the evolution of the lower respiratory tract as an evolutionary trade-off relationship between resistance and tolerance is considered to be a reason behind the susceptibility of humans to COPD.

In tissues with low tolerance, ROS produced by inflammatory cells can easily cause collateral tissue damage [74]. For example, oxidative stress tolerance through the Keap1-NF-E2-related factor 2 (NRF2) pathway, whose components include glutathione synthetase and hemoxygenase-1, requires preconditioning by mild oxidative stress $[75,76]$; the system cannot cope with acute lung injury that is associated with sudden exposure to a large amount of ROS. Activation of oxidative stress tolerance is not constitutive but inducible, probably for the following reasons. First, energy cost (consumption of free energy) is needed to constitutively activate the antioxidant system. Second, physiological levels of ROS are needed as signaling factors to maintain normal cellular activity [77]. For example, it has been pointed out that excessive 'antioxidative stress' is cytotoxic [78], and that constitutive NRF2 activation is carcinogenic [79]. Third, preconditioning for oxidative stress tolerance may occur frequently in the lung, because the lung is exposed to injurious agents from the respiratory tract and blood on a daily basis. For example, in healthy smokers, antioxidant enzymes and glutathione-dependent detoxification systems are upregulated by NRF2 activation [73]. However, it is considered that in COPD patients, such adaptation does not take place, allowing damage to occur as a result of ROS [73].

Thus, the fifth presumed reason for the development of COPD in humans is that the lower respiratory tract is susceptible to inflammatory side effects as a result of evolutionary selection of a high cost of inflammation and a low tolerance in the respiratory tract.

\section{Reproductive Success at the Expense of Health}

Higher reproductive success early in life may come at the expense of disease and mortality. For example, in humans, higher testosterone and estrogen levels cause high- 
er fertility, but also higher susceptibility to prostate and breast cancer [80]. In addition, women who reach menarche at a younger age and those with BRCA mutations have higher levels of fertility, but are also more susceptible to breast cancer [81, 82]. Similarly, men with shorter CAG repeats in the androgenic receptor gene have higher sperm viability and higher fertility [83], but they are more susceptible to prostate cancer $[49,84]$. These are good examples that explain the trade-offs between early fertility and later survival by reproduction-enhancing pathogenic traits.

It can be pointed out that reproduction-enhancing pathogenic traits may also be involved in the susceptibility to COPD. For example, some chemicals in cigarette smoke are bioactivated into toxic compounds by cytochrome $\mathrm{P}_{450}(\mathrm{CYP})$ enzymes in the lung, and estrogen is known to activate CYP1A1 and CYP1B1, enhancing the toxicity of cigarette smoke [85-88]. Furthermore, it has been reported that estrogen stimulates the production of mucin (MUC5B) in airway epithelial cells, thereby increasing sputum production [89]. These estrogen actions are considered to increase women's susceptibility to COPD $[85,86]$. In addition, it has been reported that $\beta$-defensin, which promotes the development of COPD $[45,90-92]$, facilitates sperm maturation and fertilization, thereby increasing fertility [93].

Thus, the sixth presumed reason for the development of COPD in humans involves the evolutionary costs of reproduction.

\section{Limitations of the Evolutionary Approach to Explain the Development of COPD}

The evolutionary medical approach, as described, is useful for explaining not the pathogenesis (i.e. the causes and mechanisms of COPD), but the ultimate reason why the disease occurs at all in humans. However, this approach also has its limitations. First, evolutionary medicine is not directly useful in the diagnosis and treatment of COPD. However, the concepts presented when exploring the tenets of evolutionary medicine provide information that can lead to a clearer understanding of the etiology and pathogenesis of COPD; this perspective is also necessary for researchers to better understand the significance of their work. Second, it is difficult to scientifically prove the validity of the core principles constituting the framework of evolutionary medicine. For example, it is practically impossible to experimentally prove or observe the effects of natural selection and the trade-offs

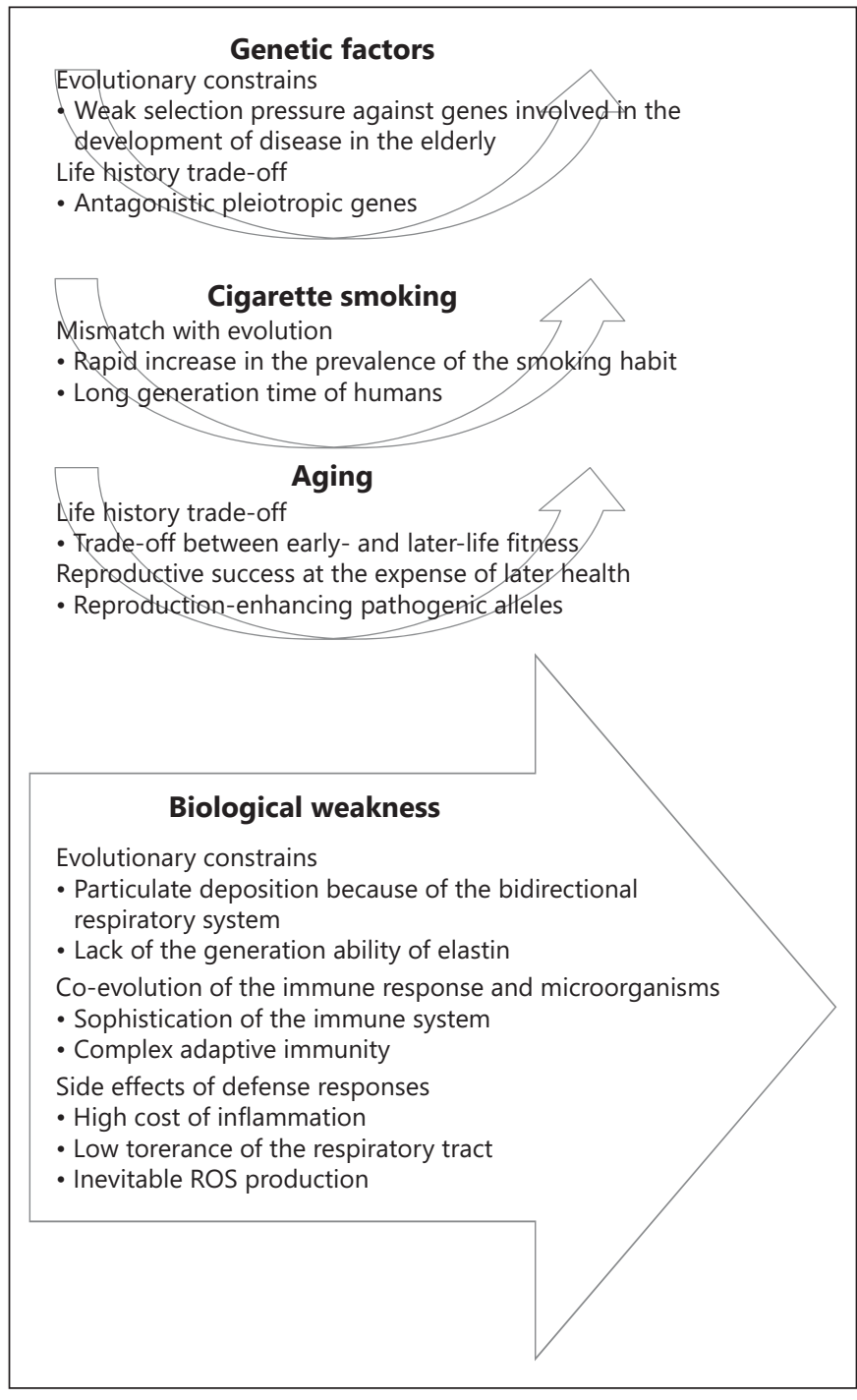

Fig. 4. Etiopathogenetic mechanism of COPD involving evolutionary factors.

between early and later life in mammalians, which have long lifespans. However, the questions asked in evolutionary medicine are the 'why' questions (for example, why diseases exist in the first place). It is difficult to scientifically prove the correctness of the answers to questions of this nature, unlike the questions about causes and mechanisms. Third, an evolutionary medical explanation for the occurrence of COPD, as described in this paper, represents one of the few opportunities for applying evolutionary principles to explain the development of COPD, as many other examples can be given. For example, it would be necessary to consider not only natural selection, but also genetic variations due to founder ef- 
fects, genetic drift and migration to explain the distribution of genetic predispositions and susceptibility traits to COPD.

\section{Conclusion}

In summary, there are at least six possible evolutionary reasons for the development of COPD in humans. The evolutionary explanations described in this paper (evolutionary constraints, mismatch between environmental changes and genes, co-evolution of pathogenic microorganisms and the immune response, trade-offs between early and later life, high cost of inflammation and low tolerance in the respiratory tract and reproductive success at the expense of health) provide new insights into the understanding of why COPD develops in humans, why many COPD patients are elderly, and why some subpopulations are more susceptible to COPD (fig. 4). In order to obtain a clearer understanding of the etiology of $\mathrm{COPD}$, it is not only necessary to elucidate any proximate factors, such as the causes and mechanisms, but also to consider the ultimate factors involved in the development of COPD.

\section{Acknowledgment}

A Grant-in-Aid for Scientific Research was obtained from the Ministry of Education, Science, and Culture, Japan.

\section{Financial Disclosure and Conflict of Interests}

None to declare.

\section{References}

Lozano R, Naghavi M, Foreman K, Lim S, Shibuya K, Aboyans V, Abraham J, Adair T, Aggarwal R, Ahn SY, Alvarado M, Anderson HR, Anderson LM, Andrews KG, Atkinson C, Baddour LM, Barker-Collo S, Bartels DH, Bell ML, Benjamin EJ, Bennett D, Bhalla K, Bikbov B, Bin Abdulhak A, Birbeck G, Blyth F, Bolliger I, Boufous S, Bucello C, Burch M, Burney P, Carapetis J, Chen H, Chou D, Chugh SS, Coffeng LE, Colan SD, Colquhoun $\mathrm{S}$, Colson KE, Condon J, Connor MD, Cooper LT, Corriere M, Cortinovis M, de Vaccaro KC, Couser W, Cowie BC, Criqui $\mathrm{MH}$, Cross M, Dabhadkar KC, Dahodwala N, De Leo D, Degenhardt L, Delossantos A, Denenberg J, Des Jarlais DC, Dharmaratne SD, Dorsey ER, Driscoll T, Duber H, Ebel B, Erwin PJ, Espindola P, Ezzati M, Feigin V, Flaxman AD, Forouzanfar MH, Fowkes FG, Franklin R, Fransen M, Freeman MK, Gabriel SE, Gakidou E, Gaspari F, Gillum RF, Gonzalez-Medina D, Halasa YA, Haring D, Harrison JE, Havmoeller R, Hay RJ, Hoen B, Hotez PJ, Hoy D, Jacobsen KH, James SL, Jasrasaria R, Jayaraman S, Johns N, Karthikeyan G, Kassebaum N, Keren A, Khoo JP, Knowlton LM, Kobusingye O, Koranteng A, Krishnamurthi R, Lipnick M, Lipshultz SE, Ohno SL, Mabweijano J, MacIntyre MF, Mallinger L, March L, Marks GB, Marks R, Matsumori A, Matzopoulos R, Mayosi BM, McAnulty JH, McDermott MM, McGrath J, Mensah GA, Merriman TR, Michaud C, Miller M, Miller TR, Mock C, Mocumbi AO, Mokdad AA, Moran A, Mulholland K, Nair MN, Naldi L, Narayan KM, Nasseri K, Norman P, O'Donnell M, Omer SB, Ortblad K, Osborne R, Ozgediz D, Pahari B, Pandian JD, Rivero AP, Padilla RP, Perez-Ruiz F, Perico
N, Phillips D, Pierce K, Pope CA 3rd, Porrini E, Pourmalek F, Raju M, Ranganathan D, Rehm JT, Rein DB, Remuzzi G, Rivara FP, Roberts T, De León FR, Rosenfeld LC, Rushton L, Sacco RL, Salomon JA, Sampson U, Sanman E, Schwebel DC, Segui-Gomez M, Shepard DS, Singh D, Singleton J, Sliwa K, Smith E, Steer A, Taylor JA, Thomas B, Tleyjeh IM, Towbin JA, Truelsen T, Undurraga EA, Venketasubramanian N, Vijayakumar L, Vos T, Wagner GR, Wang M, Wang W, Watt K, Weinstock MA, Weintraub R, Wilkinson JD, Woolf AD, Wulf S, Yeh PH, Yip P, Zabetian A, Zheng ZJ, Lopez AD, Murray CJ, AlMazroa MA, Memish ZA: Global and regional mortality from 235 causes of death for 20 age groups in 1990 and 2010: a systematic analysis for the Global Burden of Disease Study 2010. Lancet 2012;380:20952128.

2 Global Initiative for Chronic Obstructive Lung Disease (GOLD). Global strategy for the diagnosis, management, and prevention of chronic obstructive pulmonary disease: revised 2011. http://www.goldcopd.org/uploads/users/files/ GOLD_Report_2011_Jan21.pdf.

-3 Zhou JJ, Cho MH, Castaldi PJ, Hersh CP, Silverman EK, Laird NM: Heritability of COPD and related phenotypes in smokers. Am J Respir Crit Care Med 2013;188:941-987.

4 Williams GC, Nesse RM: The dawn of Darwinian medicine. Q Rev Biol 1991;66:1-22.

5 Nesse RM, Williams GC: Why We Get Sick: The New Science of Darwinian Medicine. New York, Vintage Books, 1994.

6 6 Nesse RM: Maladaptation and natural selection. Q Rev Biol 2005;80:62-70.

7 Nesse RM, Stearns SC, Omenn GS: Medicine needs evolution. Science 2006;311:1071. $\checkmark 8$ Nesse RM: Evolution: medicine's most basic science. Lancet 2008;372:S21-S27.

-9 Nesse RM, Ganten D, Gregory TR, Omenn GS: Evolutionary molecular medicine. J Mol Med (Berl) 2012;90:509-522.

10 Gregory TR: The evolution of complex organs. Evol Educ Outreach 2008;1:358-359.

-11 Stearns SC, Nesse RM, Govindaraju DR, Ellison PR: Evolutionary perspectives on health and medicine. Proc Natl Acad Sci U S A 2010; 107:1691-1695.

12 Stearns SC: Evolutionary medicine: its scope, interest and potential. Proc Biol Sci 2012;279: 4305-4321.

13 Jenkins KP, Antolin MF: Evolution and medicine. Evol Educ Outreach 2011;4:556-558.

14 Perlman RL: Evolutionary biology: a basic science for medicine in the 21st century. Perspect Biol Med 2011;54:75-88.

15 Aktipis CA, Nesse RM: Evolutionary foundations for cancer biology. Evol Appl 2013;6: 144-159.

16 Antolin MF, Jenkins KP, Bergstrom CT, Crespi BJ, De S, Hancock A, Hanley KA, Meagher TR, Moreno-Estrada A, Nesse RM, Omenn GS, Stearns SC: Evolution and medicine in undergraduate education: a prescription for all biology students. Evolution 2012;66:19912006.

17 Bernhard W, Haslam PL, Floros J: From birds to humans: new concepts on airways relative to alveolar surfactant. Am J Respir Cell Mol Biol 2004;30:6-11.

18 West JB, Watson RR, Fu Z: The human lung: did evolution get it wrong? Eur Respir J 2007; 29:11-17.

19 Pierce RA, Mariani TJ, Senior RM: Elastin in lung development and disease. Ciba Found Symp 1995;192:199-212. 
20 Shifren A, Mecham RP: The stumbling block in lung repair of emphysema: elastic fiber assembly. Proc Am Thorac Soc 2006;3:428-433.

21 Rennard S: Defective repair in COPD: the American hypothesis; in Pauwels RA, Postma DS (eds): Long-Term Intervention in Chronic Obstructive Pulmonary Disease. New York, Dekker, 2004, pp 165-200.

22 Shapiro SD, Endicott SK, Province MA, Pierce JA, Campbell EJ: Marked longevity of human lung parenchymal elastic fibers deduced from prevalence of $\mathrm{D}$-aspartate and nuclear weapons-related radiocarbon. J Clin Invest 1991;87:1824-1834.

23 Zhang J, Wu L, Qu JM, Bai CX, Merrilees MJ, Black PN: Proinflammatory phenotype of COPD fibroblasts not compatible with repair in COPD lung. J Cell Mol Med 2012;16:15221533.

24 Gwon A: Lens regeneration in mammals: a review. Surv Ophthalmol 2006;51:51-62.

25 Sharma KK, Santhoshkumar P: Lens aging: effects of crystallins. Biochim Biophys Acta 2009; 1790:1095-1108.

26 Ljubuncic P, Reznick AZ: The evolutionary theories of aging revisited - a mini-review. Gerontology 2009;55:205-216.

27 Ruhli FJ, Henneberg M: New perspectives in evolutionary medicine: the relevance of microevolution for human health and disease. BMC Med 2013;11:115.

-28 Tishkoff SA, Reed FA, Ranciaro A, Voight BF, Babbitt CC, Silverman JS, Powell K, Mortensen HM, Hirbo JB, Osman M, Ibrahim M, Omar SA, Lema G, Nyambo TB, Ghori J, Bumpstead S, Pritchard JK, Wray GA, Deloukas P: Convergent adaptation of human lactase persistence in Africa and Europe. Nat Genet 2007;39:31-40.

29 Sangani RG, Ghio AJ: Lung injury after cigarette smoking is particle related. Int J Chron Obstruct Pulmon Dis 2011;6:191-198.

30 Proctor RN: The global smoking epidemic: a history and status report. Clin Lung Cancer 2004;5:371-376.

-31 Nesse RM, Berridge KC: Psychoactive drug use in evolutionary perspective. Science 1997; 278:63-66.

32 Gold AB, Lerman C: Pharmacogenetics of smoking cessation: role of nicotine target and metabolism genes. Hum Genet, Epub ahead of print.

- 33 Woolhouse MEJ, Webster JP, Domingo E, Charlesworth B, Levin B: Biological and biomedical implications of the co-evolution of pathogens and their hosts. Nat Genet 2002;32: 569-577.

-34 Medzhitov R: Origin and physiological roles of inflammation. Nature 2008;454:428-435.

- 35 Okin D, Medzhitov R: Evolution of inflammatory diseases. Curr Biol 2012;22:R733R740.

-36 Cosio MG, Saetta M, Agusti A: Immunologic aspects of chronic obstructive disease. $\mathrm{N}$ Engl J Med 2009;360:2445-2454.

- 37 Maier KL, Alessandrini F, Beck-Speier I, Hofer TP, Diabaté S, Bitterle E, Stöger T, Ja- kob T, Behrendt H, Horsch M, Beckers J, Ziesenis A, Hültner L, Frankenberger M, Krauss-Etschmann S, Schulz H: Health effects of ambient particulate matter - biological mechanisms and inflammatory responses to in vitro and in vivo particle exposures. Inhal Toxicol 2008;20:319-337.

-38 Sethi S, Murphy TF: Infection in the pathogenesis and course of chronic obstructive pulmonary disease. N Engl J Med 2008;359: 2335-2365.

- 39 Harris P, Sridhar S, Peng R, Phillips JE, Cohn RG, Burns L, Woods J, Ramanujam M, Loubeau M, Tyagi G, Allard J, Burczynski M, Ravindran $\mathrm{P}$, Cheng $\mathrm{D}$, Bitter $\mathrm{H}$, Fine JS, Bauer CM, Stevenson CS: Double-stranded RNA induces molecular and inflammatory signatures that are directly relevant to COPD. Mucosal Immunol 2013;6:474-484.

-40 Kang MJ, Lee CG, Lee JY, Dela Cruz CS, Chen ZJ, Enelow R, Elias JA: Cigarette smoke selectively enhances viral PAMP- and virus-induced pulmonary innate immune and remodeling responses in mice. J Clin Invest 2008;118:2771-2784.

41 Meshi B, Vitalis TZ, Ionescu D, Elliott WM, Liu C, Wang XD, Hayashi S, Hogg JC: Emphysematous lung destruction by cigarette smoke. The effects of latent adenoviral infection on the lung inflammatory response. Am J Respir Cell Mol Biol 2002;26:52-57.

42 Li Y, Li SY, Li JS, Deng L, Tian YG, Jiang SL, Wang Y, Wang YY: A rat model for stable chronic obstructive pulmonary disease induced by cigarette smoke inhalation and repetitive bacterial infection. Biol Pharm Bull 2012;35:1752-1760.

43 Rangel-Moreno J, Moyron-Quiroz JE, Hartson L, Kusser K, Randall TD: Pulmonary expression of CXC chemokine ligand 13, CC chemokine ligand 19, and CC chemokine ligand 21 is essential for local immunity to influenza. Proc Natl Acad Sci U S A 2007;25: 10577-10582.

-44 Litsiou E, Semitekolou M, Galani IE, Morianos I, Tsoutsa A, Kara P, Rontogianni D, Bellenis I, Konstantinou M, Potaris K, Andreakos E, Sideras P, Zakynthinos S, Tsoumakidou M: CXCL13 production in B cells via TLR/ lymphotoxin receptor signaling are involved in lymphoid neogenesis in COPD. Am J Respir Crit Care Med 2013;187:1194-1202.

- 45 Yao TC, Du G, Han L, Sun Y, Hu D, Yang JJ, Mathias R, Roth LA, Rafaels N, Thompson EE, Loisel DA, Anderson R, Eng C, Arruabarrena Orbegozo M, Young M, Klocksieben JM, Anderson E, Shanovich K, Lester LA, Williams LK, Barnes KC, Burchard EG, Nicolae DL, Abney M, Ober C: Genome-wide association study of lung function phenotypes in a founder population. J Allergy Clin Immunol 2014;133:248-255.

46 Bosse Y: Updates on the COPD gene list. Int J Chron Obstruc Pulmon Dis 2012;7:607-631.

-47 Williams GC: Pleiotropy, natural selection, and the evolution of senescence. Evolution 1957;11:398-411.
48 Stearns S: Trade-offs in life-history evolution. Funct Ecol 1989;3:259-268.

49 Hawkes K, O’Connell JF, Blurton-Jones NG, Alvarez H, Charnov EL: Grandmothering, menopause, and the evolution of human life histories. Proc Natl Acad Sci U S A 1998;95: 1336-1339.

50 Carter AJR, Nguyen AQ: Antagonistic pleiotropy as a widespread mechanism for the maintenance of polymorphic disease alleles. BMC Med Genet 2011;12:160.

51 Aidoo M, Terlouw DJ, Kolczak MS, McElroy PD, ter Kuile FO, Kariuki S, Nahlen BL, Lal AA, Udhayakumar V: Protective effects of the sickle cell gene against malaria morbidity and mortality. Lancet 2002;359:1311-1312.

52 Knudson AG Jr, Wayne L, Hallet WY: On the selective advantage of cystic fibrosis heterozygotes. Am J Hum Genet 1967;19:388-392.

53 Gabriel SE, Brigman KN, Koller BH, Boucher RC, Stutts MJ: Cystic fibrosis heterozygote resistance to cholera toxin in the cystic fibrosis mouse model. Science 1994;266:107-109.

54 Poolman EM, Galvani AP: Evaluating candidate agents of selective pressure for cystic fibrosis. J R Soc Interface 2007;4:91-98.

55 Aoshiba K, Nagai A: An evolutionary perspective on chronic obstructive pulmonary disease. Am J Respir Cell Mol Biol 2009;41:507-508.

56 Lomas DA: The selective advantage of a1-antitrypsin deficiency. Am J Respir Crit Care Med 2006;173:1072-1077.

57 Fagerhol MK, Gedde-Dahl T Jr: Genetics of the Pi serum types. Family studies of the inherited variants of serum alpha-1-antitrypsin. Hum Hered 1969;19:354-359.

58 Fagerhol MK, Cox DW: The Pi polymorphism: genetic, biochemical, and clinical aspects of human alpha 1-antitrypsin. Adv Hum Genet 1981;11:1-62.

59 Aoshiba K, Yokohori N, Nagai A: Alveolar wall apoptosis causes lung destruction and emphysematous changes. Am J Respir Cell Mol Biol 2003;28:555-562.

60 Aoshiba K, Nagai A: Senescence hypothesis for the pathogenetic mechanism of chronic obstructive pulmonary disease. Proc Am Thorac Soc 2009;6:596-601.

61 Kirkwood TB, Austad SN: Why do we age? Nature 2000;408:233-238.

62 Wright WE, Shay J: Time, telomeres and tumors: is cellular senescence more than an anticancer mechanism? Trends Cell Biol 1995;5: 293-297.

63 Campisi J: Cancer and aging. Nat Rev Cancer 2003;3:339-349.

64 Nathan C: Points of control in inflammation. Nature 2002;420:846-852.

65 Graham AL: When T-helper cells don't help: immunopathology during concomitant infection. Q Rev Biol 2002;77:409-434.

66 Ruiz-Núñez B, Pruimboom L, Dijck-Brouwer DA, Muskiet FA: Lifestyle and nutritional imbalances associated with Western diseases: causes and consequences of chronic systemic low-grade inflammation in an evolutionary context. J Nutr Biochem 2013;24:1183-1201. 
67 Restif O, Koella JC: Concurrent evolution of resistance and tolerance to pathogens. Am Nat 2004;164:E90-E102.

68 Schneider DS, Ayres JS: Two ways to survive infection: what resistance and tolerance can teach us about treating infectious diseases. Nat Rev Immunol 2008;8:889-895.

-69 Sansonetti PJ, Medzhitov R: Learning tolerance while fighting ignorance. Cell 2009;138: 416-420.

70 Nuding S, Fellermann K, Wehkamp J, Stange EF: Reduced mucosal antimicrobial activity in Crohn's disease of the colon. Gut 2007;56: 1240-1247.

71 Raberg L, Sim D, Read AF: Disentangling genetic variation for resistance and tolerance to infectious disease in animals. Science 2007; 318:812-814

72 Cosio MG, Saetta M: Evasion of COPD in smokers: at what price? Eur Respir J 2012;39: 1298-1303.

73 Cantin AM: Cellular response to cigarette smoke and oxidants: adapting to survive. Proc Am Thorac Soc 2010;7:368-375.

74 Lambeth JD: Nox enzymes, ROS and chronic disease: an example of antagonistic pleiotropy. Free Radic Biol Med 2007;43:332-347.

-75 Osburn WO, Kensler TW: Nrf2 signaling: an adaptive response pathway for protection against environmental toxic insults. Mutat Res 2008;659:31-39.

76 Chow CK: Biomedical responses in lungs of ozone-tolerant rats. Nature 1976;260:721722.

-77 Hekimi S, Lapointe J, Wen Y: Taking a 'good' look at free radicals in the aging process. Trends Cell Biol 2011;21:569-576.
78 Poljsak B, Milisav I: The neglected significance of 'antioxidative stress'. Oxid Med Cell Longev 2012;2012:480895.

79 Shelton P, Jaiswal AK: The transcription factor NF-E2-related factor 2 (Nrf2): a protooncogene? FASEB J 2013;27:414-423.

80 Calistro Alvarado L: Population differences in the testosterone levels of young men are associated with prostate cancer disparities in older men. Am J Hum Biol 2010;22:449-455.

81 Hsieh CC, Trichopoulos D, Katsouyanni K, Yuasa S: Age at menarche, age at menopause, height and obesity as risk factors for breast cancer: associations and interactions in an intentional case-control study. Int J Cancer 1990;46:796-800.

82 Smith KR, Hanson HA, Mineau GP, Buys SS: Effects of BRCA1 and BRCA2 mutations on female fertility. Proc Biol Sci 2012;279:1389_ 1395.

83 Dowsing AT, Young EL, Clark M, McLachlan R, Krester D, Trounson A: Linkage between male infertility and trinucleotide repeat expansion in the androgen-receptor gene. Lancet 1999;354:640-643.

84 Ingles SA, Ross R, Yu M, Irvine R, La Pera G, Haile R, Coetzee G: Association of prostate cancer risk with genetic polymorphisms in vitamin D and androgen receptor. J Natl Cancer Inst 1997;89:166-170.

-85 Sin DD, Cohen SB, Day A, Coxson H, Pare PD: Understanding the biological differences in susceptibility to chronic obstructive pulmonary disease between men and women. Proc Am Thorac Soc 2007;4:671-674.

-86 Tam A, Morrish D, Wadsworth S, Dorscheid D, Paul Man SF, Sin DD: The role of female hormones on lung function in chronic lung diseases. BMC Womens Health 2011;11:24.
87 Han W, Pentecost BT, Pietropaolo RL, Fasco MJ, Spivack SD: Estrogen receptor alpha increases basal and cigarette smoke extract-induced expression of CYP1A1 and CYP1B1, but not GSTP1, in normal human bronchial epithelial cells. Mol Carcinog 2005;44:202-211.

-88 Mollerup S, Ryberg D, Hewer A, Phillips DH Haugen A: Sex differences in lung CYP1A1 expression and DNA adduct levels among lung cancer patients. Cancer Res 1999;59: 3317-3320.

89 Choi HJ, Chung YS, Kim HJ, Moon UY, Choi YH, Van Seuningen I, Baek SJ, Yoon HG, Yoon JH: Signal pathway of 17beta-estradiolinduced MUC5B expression in human airway epithelial cells. Am J Respir Cell Mol Biol 2009;40:168-178.

90 Andersen E, Günther G, Bullwinkel J, Lange C, Heine H: Increased expression of beta-defensin 1 (DEFB1) in chronic obstructive pulmonary disease. PLoS One 2011;6:e21898.

91 Liao Z, Dong J, Hu X, Wang T, Wan C, Li X, Li L, Guo L, Xu D, Wen F: Enhanced expression of human $\beta$-defensin in peripheral lungs of patients with chronic obstructive pulmonary disease. Peptides 2012;38:350-356

92 Janssens W, Nuytten H, Dupont LJ, Van Eldere J, Vermeire S, Lambrechts D, Nackaerts K, Decramer M, Cassiman JJ, Cuppens H: Genomic copy number determines functional expression of $\beta$-defensin 2 in airway epithelial cells and associates with chronic obstructive pulmonary disease. Am J Respir Crit Care Med 2010;182:163-169.

93 Semple F, Dorin JR: $\beta$-Defensins: multifunctional modulators of infection, inflammation and more? J Innate Immun 2012;4:337-348. 